Vol. 13, No. 1, pp. 38- 45

\title{
LOW TEMPERATURE ACROLEIN TO ACRYLIC ACID OXIDATION WITH HYDROGEN PEROXIDE ON SE-ORGANIC CATALYSTS
}

\author{
Roman Nebesnyi ${ }^{1}{ }^{*}$, Volodymyr Ivasiv ${ }^{1}$, Zoryan Pikh ${ }^{1}$, Tetiana Kharandiuk ${ }^{1}$, \\ Iryna Shpyrka ${ }^{1}$, Taras Voronchak ${ }^{2}$, Anastasia- Bohdana Shatan ${ }^{3}$
}

https://doi.org/10.23939/chcht13.01.038

\begin{abstract}
Catalytic performance of Se-containing organic substances, namely methylseleninic acid, benzeneseleninic acid, phenylselenol and diphenyldiselenide, has been tested as potential catalysts for unsaturated aldehydes oxidation by hydrogen peroxide. All tested substances proved to be active in the acrolein oxidation reaction but showed different efficiency regarding used solvents and the products of reaction - acrylic acid or methyl acrylate. Optimal catalyst, reaction conditions and solvent for acrylic acid synthesis have been determined.
\end{abstract}

Keywords: acrylic acid, unsaturated aldehydes, Seorganic catalysts, oxidation, hydrogen peroxide.

\section{Introduction}

The oxidation of aldehydes is a widely used reaction in organic chemistry [1]. The common oxidants used for this reaction are mainly based on heavy metals resulting in the production of large amount of wastes [2]. Alternative oxidants for this process, such as hydrogen peroxide [2-5], $\mathrm{O}_{2}$ [6-9], peracetic acid [10] and calcium hypochlorite [9] were studied. Among these oxidants aqueous $\mathrm{H}_{2} \mathrm{O}_{2}$ is of most interest due to its low cost and safety since the only formed by-product is water. However, $\mathrm{H}_{2} \mathrm{O}_{2}$ can not be used as oxidant by itself; it requires the catalyst capable of oxidant activation $[2,4,5$, $11,12] . \mathrm{H}_{2} \mathrm{O}_{2}$ can be activated by several different methods: nucleophilic, electrophilic radical activation, activation by use of transition metal derivatives, activation by organic compounds which give different and more active peroxidic species [13].

Diselenide compounds and arylseleninic acids are well known to react with hydrogen peroxide to form the corresponding peracids (Scheme 1) [14]. Some peracids

\footnotetext{
${ }^{1}$ Lviv Polytechnic National University,

12, Bandery St., 79013 Lviv, Ukraine

${ }^{2}$ Market Central Laboratory, Nestle Ukraine LLC, Lviv, Ukraine

${ }^{3}$ Institute of Macromolecular Chemistry,

Czech Academy of Sciences, Prague, Czech Republic

*roman.v.nebesnyi@lpnu.ua

(C) Nebesnyi R., Ivasiv V., Pikh Z., Kharandiuk T., Shpyrka I., Voronchak T., Shatan A.-B., 2019
}

are shown to be effective in oxidation process, e.g. diphenyl diselenide immobilized on magnetic nanoparticles. This catalyst was used for the oxidation of 2-hydroxybenzaldehyde with $\mathrm{H}_{2} \mathrm{O}_{2}$ and resulted in $98 \%$ yield [15]. Selenium was also used for the oxidation of 3,3',5,5'-tetramethylbenzidine in form of selenium nanoparticles [16], for the oxidation of 2-methylnaphtalene with SeMCM-41 (conversion $85 \%$, selectivity $68 \%$ ) [17], p-nitrobenzaldehyde oxidation with 3,5-bis(perfluorooctyl)phenyl butylselenide (90\% yield) [18] and proved to be effective in oxidation reactions.

The oxidation of acrolein to acrylic acid has been chosen as a test reaction to prove the catalytic activity of Se-containing catalysts. Acrylic acid is widely used industrial raw material, world production of which amounts to about 6 million tons annually. The conventional industrial method of acrylic acid synthesis is propylene oxidation [19-21], and one of the promising alternative (renewable) methods - glycerol oxidation [22, 23]. Both methods include the intermediate stage of acrolein formation, so the increase of the catalysts efficiency for acrolein oxidation to acrylic acid would be a very useful result. In this work we studied catalytic activity of organoselenium compounds, namely methylseleninic acid, benzeneseleninic acid, phenylselenol and diphenyldiselenide in the reaction of acrolein oxidation with $\mathrm{H}_{2} \mathrm{O}_{2}$.

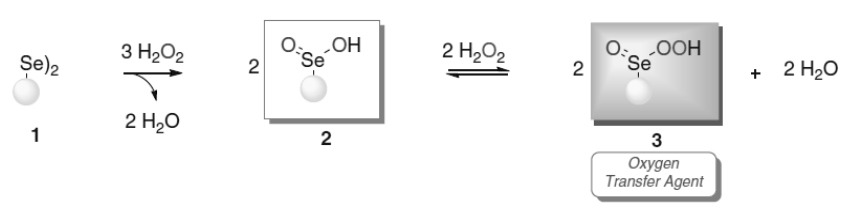

Scheme 1. Preparation of perseleninic acid 3 by reaction of diselenide 1 and seleninic acid 2 with $\mathrm{H}_{2} \mathrm{O}_{2}$ [10]

\section{Experimental}

\section{1. $M$ aterials}

Acrolein, methacrolein, crotonaldehyde, hydrogen peroxide, methanol, tert-butanol, methylseleninic acid, 
benzeneseleninic acid, phenylselenol and diphenyl diselenide were of reagent grade (Merck). The chemicals were used as received without any purification.

\subsection{Catalytic Test}

Acrolein oxidation reaction was carried out in a $25 \mathrm{ml}$ glass reactor equipped with a reflux condenser and a magnetic stirrer. The catalyst was dissolved in the solvent heated to the reaction temperature. Then aldehyde and hydrogen peroxide (the latter in the form of 35 or $60 \%$ aqueous solution) were added, and the resulting mixture was stirred under reflux for the definite time. Periodic probes after sample preparation procedure were analyzed on HP5890 SII gas chromatograph with Supelcowax10 capillary column $(30 \mathrm{~m} \times 0.53 \mathrm{~mm})$ and FID detector.

\section{Results and Discussion}

\subsection{Test of Se-Containing Organic Substances as the Catalysts for Acrolein to Acrylic Acid Oxidation with Hydrogen Peroxide}

A series of Se-containing organic substances, namely methylseleninic acid (MSA), benzeneseleninic acid (BSA), phenylselenol (PS) and diphenyldiselenide (DPDS), have been tested as the potential catalysts for unsaturated aldehydes oxidation with hydrogen peroxide

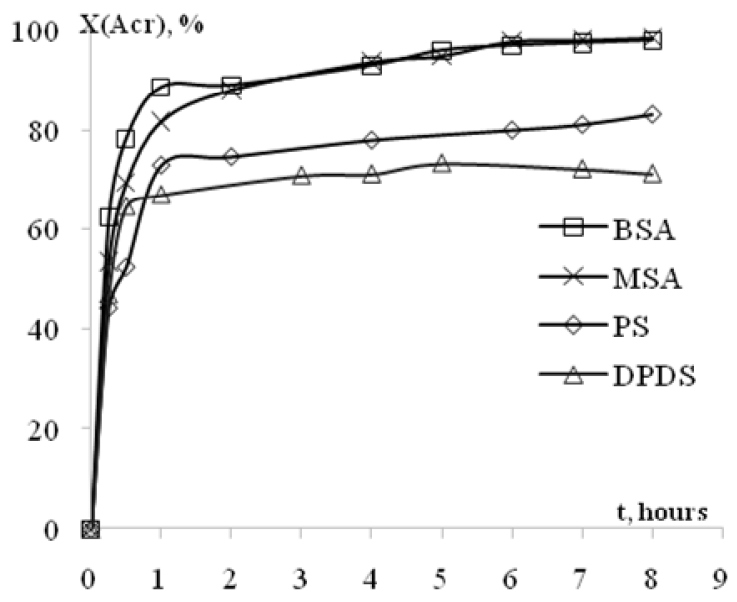

Fig.1. Dependence of $X(\mathrm{Acr})$ on the reaction time in the process of acrolein oxidation with $35 \mathrm{wt} \%$ of $\mathrm{HP}$ $\left(\mathrm{Acr} / \mathrm{HP}=1: 1.3 ; T=323 \mathrm{~K} ; C_{\text {cat. }}=0.07 \mathrm{~mol} / \mathrm{l}\right)$
(HP). The reaction was carried out in methanol medium at $323 \mathrm{~K}$ and catalyst (Se groups) concentration of $0.07 \mathrm{~mol} / \mathrm{l}$. Acrolein/HP molar ratio was 1:1.3. Apart from acrylic acid, the methyl acrylate (MA) was also formed in methanol medium. The process parameters such as acrolein conversion $X(\mathrm{Acr})$, the selectivity of acrylic acid and methyl acrylate formation $S(\mathrm{AA}), S(\mathrm{MA})$, as well as their yields $Y$ (AA), $Y$ (MA) were calculated based on the results of reaction mixture analyses. The results obtained are represented in Figs. 1-5.

Under given conditions all tested catalysts show high conversion of acrolein. The highest conversion is observed with BSA and MSA as the catalysts. The value of $X(A c r)$ is about $89 \%$ for $1 \mathrm{~h}$ and then increases to nearly $100 \%$. With PS and DPDS the maximum $X$ (Acr) is about $83 \%$ and $71 \%$, respectively.

As can be concluded from Fig. 1, in terms of $X$ (Acr) there is no reason to carry out the reaction for more than $3 \mathrm{~h}$.

Selectivity of AA formation varies in a broad range depending on the catalyst used. The pattern is opposite to one obtained for $X($ Acr $)$ : the highest $S(\mathrm{AA})$ is obtained with DPDS $(\sim 50 \%)$ and the lowest one - with MSA $(\sim 15 \%)$.

It should be also noted that $S(\mathrm{AA})$ increases in time. This indicates that dominant reaction of methyl acrylate formation (Fig. 4) proceeds with the higher rate than the target reaction. This becomes especially clear when comparing $X($ Acr) curve and $S(\mathrm{AA}), S(\mathrm{MA})$ curves for MSA (Figs. 1, 2, 4).

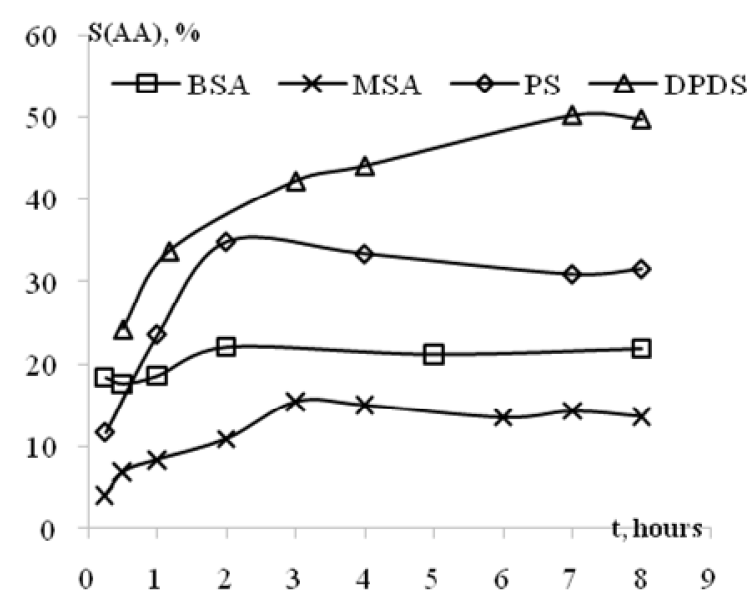

Fig. 2. Dependence of $S(\mathrm{AA})$ on the reaction time in the process of acrolein oxidation with $35 \mathrm{wt} \%$ of $\mathrm{HP}$ $\left(\mathrm{Acr} / \mathrm{HP}=1: 1.3 ; T=323 \mathrm{~K} ; C_{\text {cat }}=0.07 \mathrm{~mol} / \mathrm{l}\right)$ 


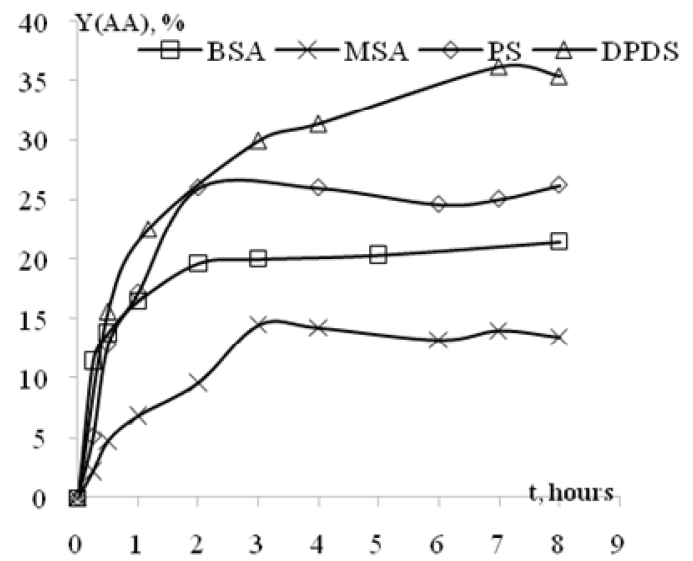

Fig. 3. Dependence of $Y(\mathrm{AA})$ on the reaction time in the process of acrolein oxidation with $35 \mathrm{wt} \%$ of $\mathrm{HP}$ $\left(\mathrm{Acr} / \mathrm{HP}=1: 1.3 ; T=323 \mathrm{~K} ; C_{\text {cat. }}=0.07 \mathrm{~mol} / \mathrm{l}\right)$

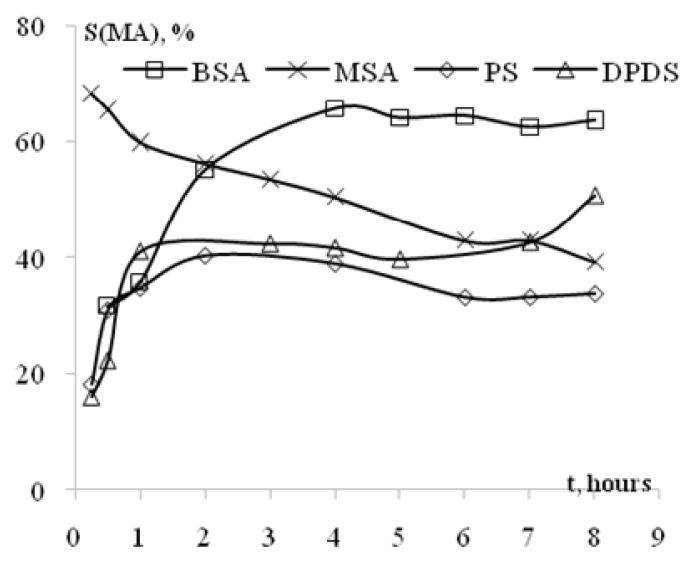

Fig. 4. Dependence of $S(\mathrm{MA})$ on reaction time in the process of acrolein oxidation with $35 \mathrm{wt} \%$ of $\mathrm{HP}$ $\left(\mathrm{Acr} / \mathrm{HP}=1: 1.3 ; T=323 \mathrm{~K} ; C_{\text {cat. }}=0.07 \mathrm{~mol} / \mathrm{l}\right)$

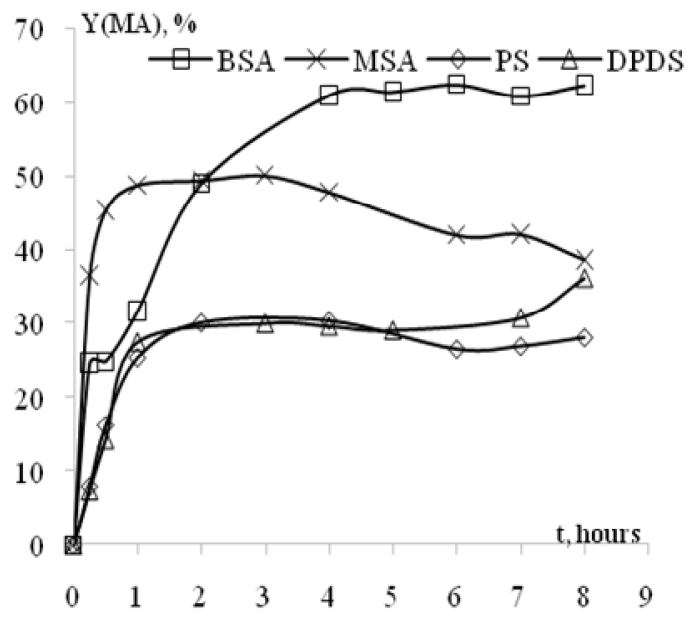

Fig. 5. Dependence of $Y(\mathrm{MA})$ on reaction time in the process of acrolein oxidation with $35 \mathrm{wt} \%$ of $\mathrm{HP}$

$\left(\mathrm{Acr} / \mathrm{HP}=1: 1.3 ; T=323 \mathrm{~K} ; C_{\text {cat. }}=0.07 \mathrm{~mol} / \mathrm{l}\right)$

Since $X($ Acr $)$ is high for all tested catalyst, the behaviour for $Y(\mathrm{AA})$ looks almost the same as for $S(\mathrm{AA})$. Acrylic acid yield increases in the series:

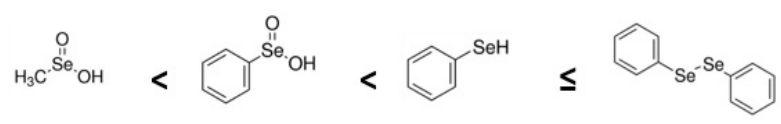

Contrary to acrylic acid selectivity, the highest value of $S$ (MA) (Fig. 4) is obtained when BSA is used $(\sim 65 \%)$ and the lowest one - for PS catalyst $(\sim 33 \%)$. Methyl acrylate yield (Fig. 5) increases in the series:

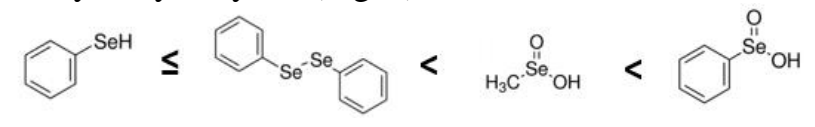

Analysing the results, BSA and MSA demonstrate almost the same values of acrolein conversion, but the latter catalyst has much lower AA selectivity, and, after $2 \mathrm{~h}$ of the reaction proceeding the MA selectivity becomes lower too. Unexpectedly, DPDS and PS, while presumably oxidizing in situ to the same intermediate benzeneperseleninic acid as BSA, demonstrate lower acrolein conversion and much higher AA selectivity, with DPDS giving the highest AA yield among tested catalysts. To clarify the reasons for such behaviour further researches are needed.

Thus, all tested catalysts can be considered as efficient catalysts for the studied reaction, but among them DPDS is the most efficient for acrylic acid production and BSA - for methyl acrylate production. Since the most considerable 
increase of $Y(\mathrm{AA})$ is observed during first three hours (Fig. 3), we consider this time interval as the optimal process time for AA production.

The yield of acrylic acid achieved with the most efficient catalyst (DPDS) for acrylic acid synthesis for the optimal process time $(3 \mathrm{~h})$ is about $30 \%$. The highest methyl acrylate yield (about $60 \%$ ) was achieved with BSA catalyst after $4^{\text {th }}$ hour of reaction and remained the same with further increase in time.

\subsection{Testing of Diphenyl Diselenide as a Catalyst for Other Aldehydes Oxidation}

Considering good efficiency of DPDS for acrolein oxidation, naturally it was interesting to test the catalyst

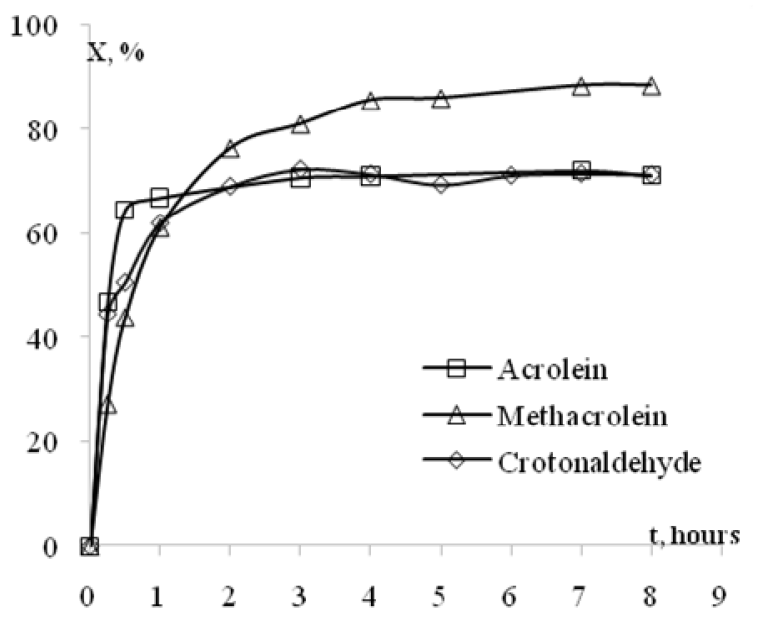

Fig. 6. Dependence of the unsaturated aldehyde conversion on the reaction time in the process of aldehyde oxidation with

$35 \mathrm{wt} \%$ of $\mathrm{HP}$ (Aldehyde/HP $=1: 1.3 ; T=323 \mathrm{~K}$;

$$
\left.C_{\text {cat. }}=0.035 \mathrm{~mol} / \mathrm{l}\right)
$$

behaviour in oxidation of other unsaturated aldehydes to corresponding acids. Methacrolein and crotonaldehyde were chosen for the experiments, and the conditions were the same as those for acrolein oxidation.

Despite the similar structure of aldehydes, the parameters of their catalytic oxidation with HP are different (Figs. 6-8).

The conversion of all three aldehydes occurs most quickly in first 3 hours and further changes very slightly.

Crotonaldehyde has roughly the same conversion as acrolein - about $70 \%$ after $3 \mathrm{~h}$. Methacrolein, which is slower converted during first hour of the reaction, has even higher conversion - up to $88 \%$.

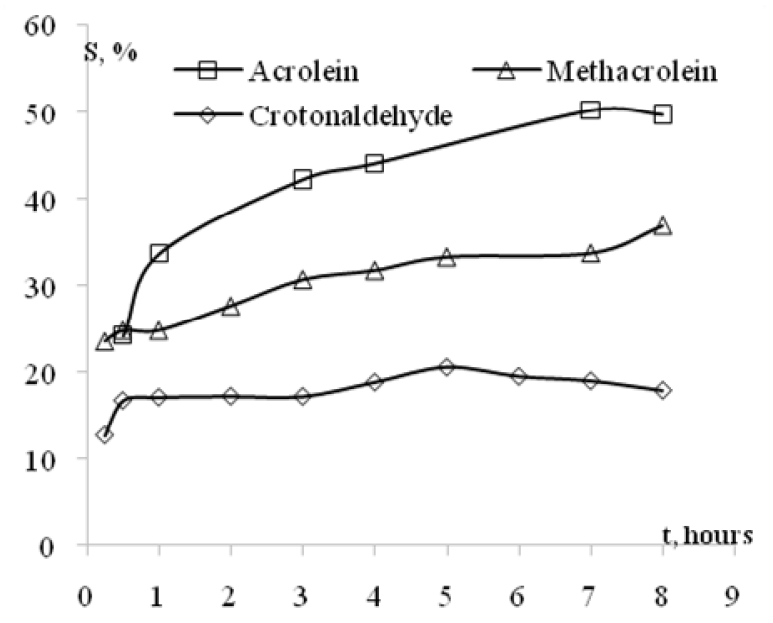

Fig. 7. Dependence of the unsaturated acid formation selectivity on the reaction time in the process of aldehydes oxidation with $35 \mathrm{wt} \%$ of $\mathrm{HP}$ (Aldehyde/HP = 1:1.3; $\left.T=323 \mathrm{~K} ; C_{\text {cat. }}=0.035 \mathrm{~mol} / \mathrm{l}\right)$

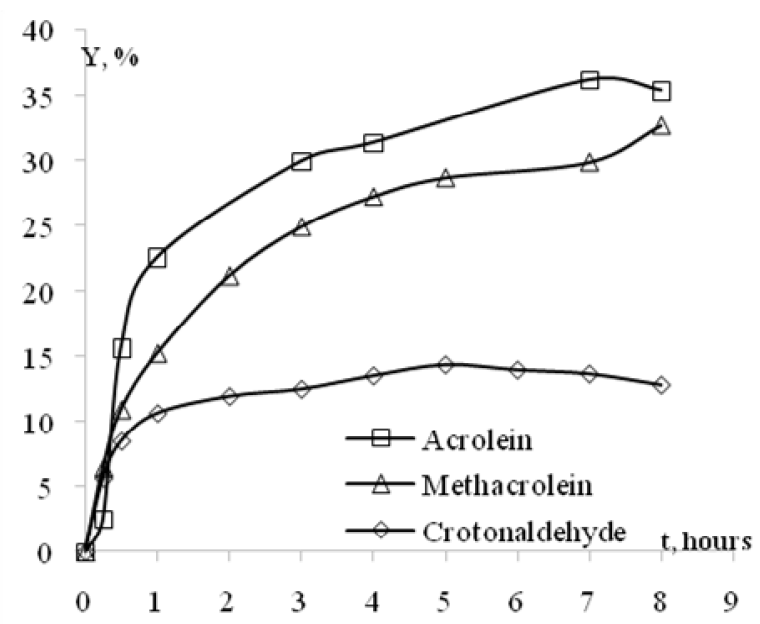

Fig. 8. Dependence of the unsaturated acid yield on the reaction time in the process of aldehydes oxidation with $35 \mathrm{wt} \%$ of $\mathrm{HP}$

(Aldehyde/HP $=1: 1.3 ; T=323 \mathrm{~K} ; C_{c a t}=0.035 \mathrm{~mol} / \mathrm{l}$ ) 
Selectivity of corresponding unsaturated acid formation (Fig. 7) decreases in the series:

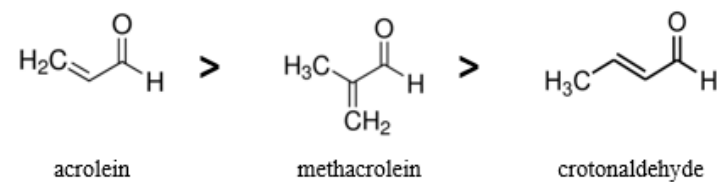

Selectivity of acrylic and methacrylic acids increases with reaction time and reaches 50 and $37 \%$, respectively. Selectivity of crotonic acid remains almost unchanged - about 17-20\%.

Even though methacrolein has higher conversion, the methacrylic acid yield is lower than acrylic acid one due to much lower selectivity. Low selectivity also determines the lowest yield of crotonic acid - $14 \%$ (Fig. 8 ). The final conclusion however, can be made only after comparing the results obtained in the optimal conditions determined individually for each aldehyde; this needs further researches.

\subsection{Study of Optimal Conditions for Acrylic Acid Synthesis with Diphenyl Diselenide as a Catalyst}

Having found the most efficient Se-organic catalyst for the acrylic acid synthesis, the next objective was to determine the optimal conditions to carry out the process with this catalyst.

\subsubsection{Catalyst concentration}

DPDS is rather expensive substance, so it is reasonable to use as low DPDS concentration as possible. At the same time the catalyst concentration must provide high process efficiency. To check the possibility of DPDS concentration reduction the experiments were carried out with the catalyst concentrations two times higher $(0.14)$ and four times lower (0.0175) than previously used ( $0.07 \mathrm{~mol} / \mathrm{l}$, calculated as mol of Se-groups per liter).

The decrease of the catalyst concentration to $0.0175 \mathrm{~mol} / \mathrm{l}$ leads to much slower increase of acrolein conversion with the reaction time, though maximum (about $70 \%$ ) achieved after $7 \mathrm{~h}$ is almost the same as for $C_{\text {cat }}=0.07 \mathrm{~mol} / \mathrm{l}$. The increase of the catalyst concentration to $0.14 \mathrm{~mol} / \mathrm{l}$ increases the conversion up to $87 \%$ (Fig. 9).

The results obtained for $S(\mathrm{AA})$ seem to be interesting (Fig. 10), because the highest selectivity is observed in the case of the catalyst intermediate concentration, while both the lowest and the highest values of $C_{\text {cat. }}$ result in lower $S(\mathrm{AA})$. So, the dependence of $S$ (AA) on DPDS concentration has a maximum at a certain value of $C_{\text {cat }}$.

It can be assumed that some side reactions are not influenced by the catalyst (probably non-oxidative reactions). The increase of the catalyst concentration to some extent promotes the target reaction and does not affect the above mentioned non-catalytic side reactions. But, when the catalyst concentration becomes too high, this, probably, leads to undesirable deeper oxidation of the target product (up to $\mathrm{CO}_{2}$ ), and hence, $S(\mathrm{AA})$ decreases.

Dependence of $Y(\mathrm{AA})$ on time and DPDS concentration (Fig. 11) allows to draw an unambiguous conclusion that $C_{\text {cat. }}=0.07 \mathrm{~mol} / \mathrm{l}$ is an optimal concentration (among studied values). The increase of the catalyst concentration leads to lower selectivity, and the decrease - to lower conversion and selectivity, thus resulting in lower AA yield.

\subsubsection{Reaction temperature}

The studies described above were conducted at $323 \mathrm{~K}$, which is almost maximum possible temperature at which the process in the liquid phase under atmospheric pressure is carried out (boiling point of acrolein is $326 \mathrm{~K}$ ). To check the possibility of proceeding the process at lower temperatures the experiments were carried out at 313 and $293 \mathrm{~K}$.

Unfortunately, the reduction of the reaction temperature even by $10 \mathrm{~K}$ results in a dramatic decrease in acrylic acid selectivity, even though acrolein conversion does not change much (Fig. 12).

For instance, after $8 \mathrm{~h}$ the value of $S(\mathrm{AA})$ is $50 \%$ at $323 \mathrm{~K}$, but only $40 \%$ at $313 \mathrm{~K}$. The temperature decrease to $293 \mathrm{~K}$ does not affect acrylic acid selectivity, but leads to significantly lower conversion. Consequently, the acrylic acid yield steadily decreases with the temperature (Fig. 12).

Thus, the reaction temperature decrease is detrimental for the AA yield, so the maximum possible reaction temperature of $323 \mathrm{~K}$ can be assumed as optimal one for the liquid phase catalytic process of acrolein oxidation with HP.

\subsubsection{Hydrogen peroxide solution concentra- tion and acrolein/ hydrogen peroxide ratio}

The HP used as an oxidant in all experiments was studied in the form of $35 \mathrm{wt} \%$ aqueous solution. Water (65 wt \%), obviously, affects the process parameters via participation in certain reactions as a reactant or shifts the equilibrium in equilibrium reactions. To ascertain the influence of extra water in the reaction mixture, we carried out experiments with HP concentration equal to $60 \mathrm{wt} \%$. Another way to reduce amount of water in the reaction mixture is to increase the acrolein/hydrogen peroxide ratio Acr/HP. In addition to the ratio $\mathrm{Acr} / \mathrm{HP}=1: 1.3$ we carried out the experiments with Acr/HP = 1:1.

Experiments were carried out under optimal conditions defined above: DPDS, $C_{\text {cat. }}=0.07 \mathrm{~mol} / \mathrm{l}$, $T=323 \mathrm{~K}$, and process time $3 \mathrm{~h}$. 


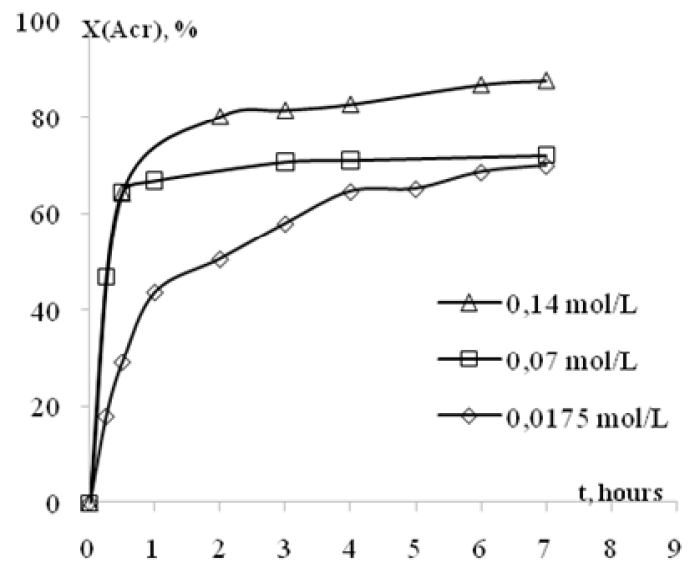

Fig. 9. Dependence of $X(\mathrm{Acr})$ on the reaction time and DPDS concentration in the process of acrolein oxidation with $35 \mathrm{wt} \%$ of $\mathrm{HP}(\mathrm{Acr} / \mathrm{HP}=1: 1.3 ; T=323 \mathrm{~K})$

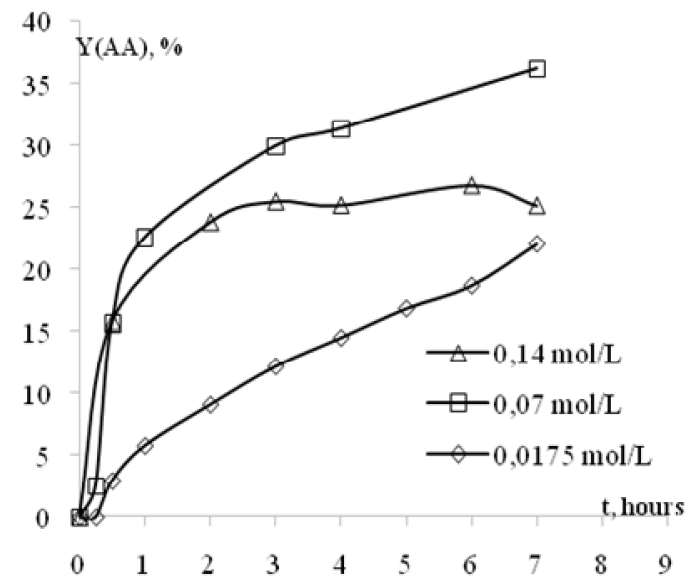

Fig. 11. Dependence of $Y(\mathrm{AA})$ on the reaction time and DPDS concentration in the process of acrolein oxidation with $35 \mathrm{wt} \%$ of $\mathrm{HP}(\mathrm{Acr} / \mathrm{HP}=1: 1.3 ; T=323 \mathrm{~K})$

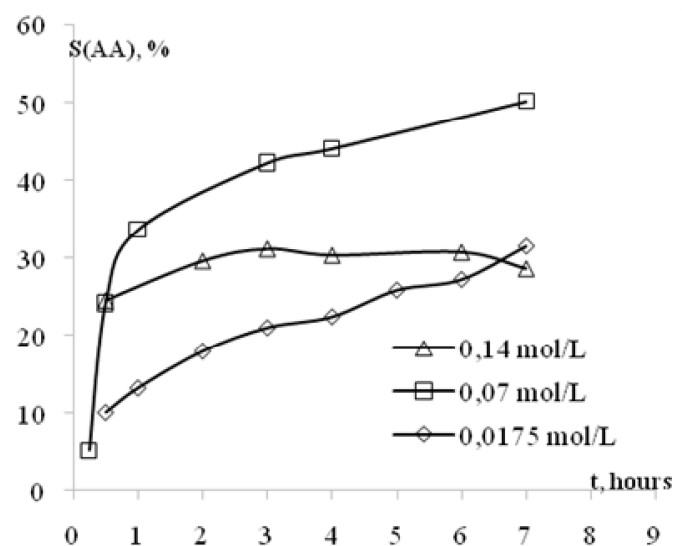

Fig. 10. Dependence of $S(\mathrm{AA})$ on the reaction time and DPDS concentration in the process of acrolein oxidation with $35 \mathrm{wt} \%$ of $\mathrm{HP}(\mathrm{Acr} / \mathrm{HP}=1: 1.3 ; T=323 \mathrm{~K})$

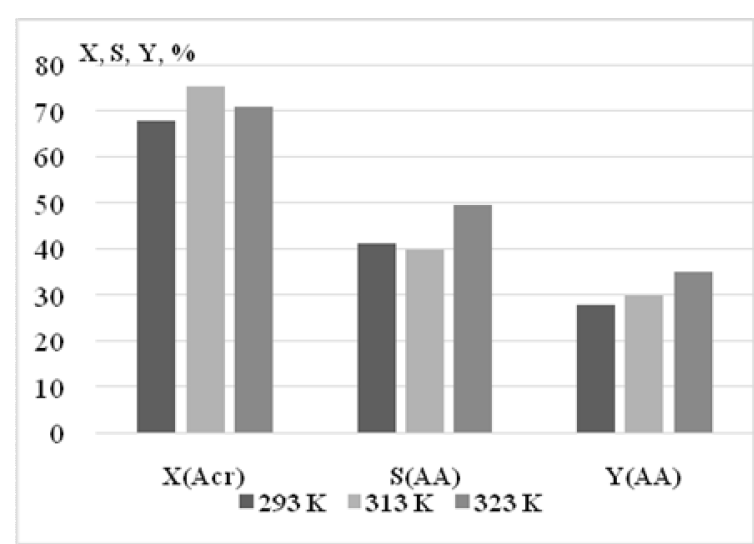

Fig. 12. Dependence of $X(\mathrm{Acr}), S(\mathrm{AA})$ and $Y(\mathrm{AA})$ on the reaction temperature in the process of acrolein oxidation with $35 \mathrm{wt} \%$ of $\mathrm{HP}\left(\mathrm{Acr} / \mathrm{HP}=1: 1.3 ; C_{\text {cat. }}\right.$ is $0.035 \mathrm{~mol} / \mathrm{l}$; DPDS is a catalyst; reaction time is $8 \mathrm{~h}$ )

Table 1

Dependence of $X(\mathrm{Acr}), S(\mathrm{AA}), S(\mathrm{MA})$ and $Y(\mathrm{AA}+\mathrm{MA})$ on time, hydrogen peroxide solution concentration and acrolein/hydrogen peroxide ratio in the process of acrolein oxidation

\begin{tabular}{|c|c|c|c|c|c|c|c|c|c|c|c|c|}
\hline & \multicolumn{3}{|c|}{$20 \mathrm{~min}$} & \multicolumn{3}{|c|}{$30 \mathrm{~min}$} & \multicolumn{3}{|c|}{$1 \mathrm{~h}$} & \multicolumn{3}{|c|}{$3 \mathrm{~h}$} \\
\hline & \multicolumn{3}{|c|}{$\begin{array}{l}\text { HP concentration / } \\
\text { Acrolein: HP ratio }\end{array}$} & \multicolumn{3}{|c|}{$\begin{array}{l}\text { HP concentration / } \\
\text { Acrolein: HP ratio }\end{array}$} & \multicolumn{3}{|c|}{$\begin{array}{l}\text { HP concentration / } \\
\text { Acrolein: HP ratio }\end{array}$} & \multicolumn{3}{|c|}{$\begin{array}{l}\text { HP concentration / } \\
\text { Acrolein: HP ratio }\end{array}$} \\
\hline & $\begin{array}{c}60 \% / \\
1: 1\end{array}$ & $\begin{array}{l}60 \% / \\
1: 1.3\end{array}$ & $\begin{array}{l}35 \% / \\
1: 1.3\end{array}$ & $\begin{array}{c}60 \% / \\
1: 1\end{array}$ & $\begin{array}{l}60 \% / \\
1: 1.3\end{array}$ & $\begin{array}{l}35 \% / \\
1: 1.3\end{array}$ & $\begin{array}{c}60 \% / \\
1: 1\end{array}$ & $\begin{array}{c}60 \% / \\
1: 1.3\end{array}$ & $\begin{array}{l}35 \% / \\
1: 1.3\end{array}$ & $\begin{array}{c}60 \% / \\
1: 1\end{array}$ & $\begin{array}{l}60 \% / \\
1: 1.3\end{array}$ & $\begin{array}{l}35 \% / \\
1: 1.3\end{array}$ \\
\hline$X(\mathrm{Acr})$ & 58 & 68 & 38 & 60 & 74 & 65 & 62 & 77 & 67 & 70 & 79 & 71 \\
\hline$S(\mathrm{AA})$ & 25 & 20 & 24 & 26 & 23 & 32 & 26 & 22 & 36 & 23 & 21 & 41 \\
\hline$S(\mathrm{MA})$ & 32 & 50 & 22 & 36 & 57 & 31 & 44 & 59 & 44 & 43 & 61 & 46 \\
\hline$Y(\mathrm{AA})$ & 14 & 13 & 13 & 16 & 15 & 18 & 16 & 17 & 23 & 16 & 16 & 32 \\
\hline$Y(\mathrm{MA})$ & 18 & 34 & 12 & 21 & 39 & 17 & 27 & 45 & 19 & 30 & 49 & 36 \\
\hline$Y(\mathrm{AA}+\mathrm{MA})$ & 33 & 47 & 25 & 37 & 54 & 35 & 43 & 62 & 52 & 46 & 65 & 68 \\
\hline
\end{tabular}

Notes: $T=323 \mathrm{~K}$; DPDS is the catalyst $(0.07 \mathrm{~mol} / \mathrm{l})$ 
Dependence of $X(\mathrm{Acr}), S(\mathrm{AA}), S(\mathrm{MA})$ and $Y(\mathrm{AA}+\mathrm{MA})$ on the reaction time and solvent nature in process of acrolein oxidation with 60 wt \% of HP

\begin{tabular}{|c|c|c|c|c|c|c|c|c|}
\hline & \multicolumn{2}{|c|}{$20 \mathrm{~min}$} & \multicolumn{2}{c|}{$30 \mathrm{~min}$} & \multicolumn{2}{c|}{$1 \mathrm{~h}$} & \multicolumn{2}{c|}{$3 \mathrm{~h}$} \\
\cline { 2 - 9 } & Methanol & tert-butanol & Methanol & tert-butanol & Methanol & tert-butanol & Methanol & tert-butanol \\
\hline$X$ (Acr) & 68 & 64 & 74 & 70 & 77 & 81 & 79 & 87 \\
\hline$S$ (AA) & 20 & 85 & 20 & 86 & 22 & 87 & 21 & 80 \\
\hline$S$ (MA) & 50 & - & 53 & - & 59 & - & 61 & - \\
\hline$Y$ (AA) & 14 & 55 & 15 & 60 & 17 & 70 & 15 & 69 \\
\hline$Y$ (MA) & 34 & - & 39 & - & 45 & - & 49 & - \\
\hline$Y$ (AA+MA) & 48 & 55 & 54 & 60 & 62 & 70 & 64 & 69 \\
\hline
\end{tabular}

Notes: Acr $/ \mathrm{HP}=1: 1.3 ; T=323 \mathrm{~K}$; DPDS is the catalyst $(0.07 \mathrm{~mol} / \mathrm{l})$

As it is shown in Table 1, the increase of HP solution concentration to $60 \mathrm{wt} \%$ leads to the increase of acrolein conversion by $8-15 \%$; the conversion increases faster with the reaction time and the maximum is about $79 \%$. So, the reduction of water amount in the reaction mixture promotes acrolein conversion and vice versa.

The increase of Acr/HP molar ratio to $1: 1$ has negative effect on acrolein conversion, despite a reduced amount of water in the reaction mixture. So, the excess of oxidant is necessary to obtain satisfactory conversion of acrolein.

When summarizing the selectivity values (Table 1), a simple conclusion can be drawn: the higher the water concentration in the reaction mixture, the higher selectivity of acrylic acid formation. Since the process is carried out in methanol, the reaction of acrolein oxidative esterification with methanol to methyl acrylate takes place. In this case methyl acrylate is the main product of the process. Water in the reaction mixture may participate in methyl acrylate hydrolysis to acrylic acid. It is the most probable reason, why acrylic acid selectivity increases with the increase of water amount. Total selectivity of AA and MA remains almost the same, but the products ratio changes. Considering this, the highest acrylates yield can be achieved after $1 \mathrm{~h}$ of the reaction using $60 \mathrm{wt} \%$ of HP versus to $3 \mathrm{~h}$ in case of $35 \mathrm{wt} \% \mathrm{HP}$.

Thus, it can be concluded that more concentrated HP solution allows to reduce the reaction time but in methanol medium the products ratio changes in favour of methyl acrylate.

\subsubsection{Solvent nature}

As it was already mentioned above, when the process is carried out with methanol as a solvent, the latter reacts with acrolein to give methyl acrylate. The acid and its ester are formed simultaneously in this case. To determine the solvent effect on the process we carried out the experiments with tert-butanol as a solvent instead of methanol. tert-Butanol has very poor reactivity because of its structure making hydroxyl group hardly accessible. So, unlike methanol, it does not form ester, and acrylic acid is the single target product.

When carrying out acrolein oxidation under the same conditions but with tert-butanol as a solvent, acrolein conversion is higher by $4-6 \%$ (Table 2). After $3 \mathrm{~h}$, for example, it is equal to $84 \%$ with tert-butanol and $78 \%$ with methanol.

The selectivity of acrylic acid in methanol is almost constant throughout the process, while methyl acrylate selectivity is low at the beginning, then increases, and after $1 \mathrm{~h}$ remains almost constant. The fact that $S(\mathrm{MA})$ is about three times higher than $S(\mathrm{AA})$ indicates that most of the acid is converted to the ester.

With tert-butanol as a solvent, the selectivity of acrylic acid is not only considerably higher than that with methanol (which is expected since ester is not formed), but curiously is higher than total AA and MA selectivity in methanol. Consequently, considering also higher acrolein conversion, the acrylic acid yield in tert-butanol is also higher than $Y(\mathrm{AA}+\mathrm{MA})$ in methanol. Thus, tertbutanol is more favourable for acrylates formation and, despite being more expensive, can be recommended to be used as a solvent for acrolein oxidation, especially in the case when the acid is a more desirable product.

\section{Conclusions}

Methylseleninic acid, benzeneseleninic acid, phenylselenol and diphenyldiselenide were tested as the catalysts for acrolein oxidation reaction with hydrogen peroxide. All catalysts proved to be active in oxidation reaction and by their ability to produce acrylic acid can be placed in the series: MSA $<$ BSA $<$ PS $<$ DPDS. Regarding the methyl acrylate yield the order of catalyst activity is another: PS < DPDS < MSA < BSA. Therefore, the most efficient catalyst for acrylic acid synthesis is diphenyldiselenide and for methyl acrylate benzeneseleninic acid. Optimal reaction conditions for 
DPDS catalyst based on acrylic acid yield are: catalyst (Se groups) concentration is $0.07 \mathrm{~mol} / \mathrm{l}$, the reaction temperature is $323 \mathrm{~K}$, the reaction time is $3 \mathrm{~h}$, hydrogen peroxide concentration is $60 \mathrm{wt} \%$, acrolein: $\mathrm{H}_{2} \mathrm{O}_{2}$ ratio is $1: 1.3$, the solvent is tert-butanol. Under optimal reaction condition the acrylic acid yield is $69 \%$. Hydrogen peroxide concentration (water content) affects the products ratio (acid/ester), i.e. the higher water content leads to the increase of acid yield. Nevertheless, lower water content caused higher methyl acrylate yield as well as higher total rate of product formation. Therefore, the products ratio can be regulated by water content in the reaction mixture. Diphenyldiselenide is also active in oxidation of other tested aldehydes (methacrolein, crotonealdehyde), but the yields of methacrylic and crotonic acids were lower than that of acrylic acid.

\section{Acknowledgements}

The authors thank Volkswagen Stiftung for the project A115859 funding.

\section{References}

[1] Esmaeili A., Kakavand S.: Comptes Rendus Chimie, 2006, 19, 936. https://doi.org/10.1016/j.crci.2016.02.009

[2] Zhou L., Donga B., Tang S. et al.: J. Energy Chem., 2013, 22, 659. https://doi.org/10.1016/S2095-4956(13)60087-X

[3] Sato K., Hyodo M., Takagi J. et al.: Tetrahedron Lett., 2000, 41, 1439. https://doi.org/10.1016/S0040-4039(99)02310-2

[4] Balinge K., Khiratkar A., Bhagat P.: J. Mol. Liq., 2017, 242, 1085. https://doi.org/10.1016/j.molliq.2017.07.105

[5] Singh S., Patel A., Prakashan P.: Appl. Catal. A., 2015, 505, 131. https://doi.org/10.1016/j.apcata.2015.07.032

[6] Hajimohammadi M., Safari N., Mofakham H. et al.: Tetrahedron Lett., 2010, 51, 4061. https://doi.org/10.1016/j.tetlet.2010.05.124

[7] Guo H., Kemell M., Al-Hunaiti A. et al.: Catal. Commun., 2011, 12, 1260. https://doi.org/10.1016/j.catcom.2011.04.025

[8] Nwaukwa S., Keehn P.: Tetrahedron Lett., 1982, 23, 3131. https://doi.org/10.1016/S0040-4039(00)88577-9

[9] Marsden C., Taarning E., Hansen D. et al.: Green Chem., 2008, 10, 168. https://doi.org/10.1039/B712171G

[10] Pikh Z., Nebesnyi R., Ivasiv V. et al.: Chem. Chem. Technol., 2016, 10, 401. https://doi.org/10.23939/chcht10.04.401

[11] Alberto E., Braga A.: Activation of Peroxides by

Organoselenium Catalysts: A Synthetic and Biological Perspective. [in:] Woollins J., Laitinen R. (Eds.), Selenium and Tellurium Chemistry. Springer, Berlin, Heidelberg 2011, 251-283.

https://doi.org/10.1007/978-3-642-20699-3_11

[12] Pikh Z., Ivasiv V.: Chem. Chem. Technol., 2012, 6, 9.

[13] Goti A., Cardona F.: Green Chem. React., 2008, 191.

[14] Hori T., Sharpless K.: J. Org. Chem., 1978, 43, 1689.

https://doi.org/10.1021/jo00403a015

[15] Rangraz Y., Nemati F., Elhampour A.: J. Colloid Interf. Sci.,

2018, 509, 485. https://doi.org/10.1016/j.jcis.2017.09.034

[16] Guo L., Huang K., Liu H.: J. Nanopart. Res., 2016, 18, 74.

https://doi.org/10.1007/s11051-016-3357-6

[17] Narender N., Suresh Kumar Reddy K., Krishna Mohan K. et

al.: J. Porous Mater., 2011, 18, 337. https://doi.org/10.1007/s10934010-9383-3

[18] Brink G.-J., Vis J., Arends I. et al.: Tetrahedron, 2002, 58, 3977. https://doi.org/10.1016/S0040-4020(02)00248-X

[19] Landi G., Lisi L., Russo G.: J. Mol. Catal., 2005, 239, 172.

https://doi.org/10.1016/j.molcata.2005.06.018

[20] Tanimoto M., Nakamura D., Kawajiri T.: Pat. US 6545178, Publ. Apr. 8, 2003.

[21] Mamoru A.: J. Catal., 1986, 101, 473.

https://doi.org/10.1016/0021-9517(86)90274-5

[22] Talebian-Kiakalaieh A., Amin N.A., Hezaveh H.: Renew. Sust. Energ. Rev., 2014, 40, 28. https://doi.org/10.1016/j.rser.2014.07.168 [23] Liu R., Lyu S., Wang T.: J. Ind. Eng. Chem., 2016, 37, 354. https://doi.org/10.1016/j.jiec.2016.03.050

Received: August 02, 2018 / Revised: August 20, 2018 / Accepted: August 30, 2018

\section{НИЗЬКОТЕМПЕРАТУРНЕ ОКИСНЕННЯ АКРОЛЁ̈НУ ДО АКРИЛОВОЇ КИСЛОТИ ПЕРОКСИДОМ ВОДНЮ НА Sе-ОРГАНІЧНИХ КАТАЛІЗАТОРАХ}

Анотація. Досліджено каталітичну активність Seвмісних органічних сполук, зокрема метилселенінової кислоти, бензенселенінової кислоти, фенілселенолу та дифенілдиснленіду як потенційних каталізаторів окиснення ненасичених альдегідів пероксидом водню. Встановлено, щзо всі протестовані сполуки є активними в досліджуваній реакиії $i$ характеризуються різною ефективністю залежно від продукту реакиї - акрилової кислоти чи метилакрилату. Встановлені оптимальні умови здійснення процесу, каталізатор та розчинник для одержання акрилової кислоти.

Ключові слова: акрилова кислота, ненасичені альдегіди, Sе-органічні каталізатори, окиснення, пероксид водню. 